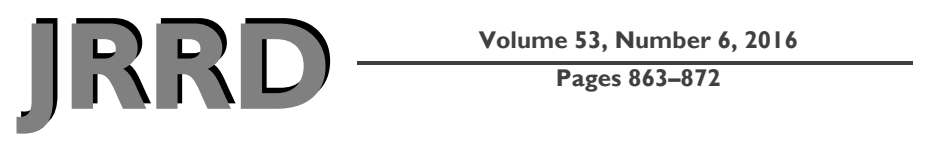

\title{
Cognitive reserve and executive function: Effect on judgment of health and safety
}

\author{
Kristin H. Hinrichs, MS; ${ }^{*}$ Alex Hayek; ${ }^{1}$ David Kalmbach, MA; ${ }^{1}$ Nicolette Gabel, PhD; ${ }^{2}$ Linas A. Bieliauskas, PhD $^{\mathbf{1 , 3}}$ \\ Departments of ${ }^{1}$ Psychiatry and ${ }^{2}$ Physical Medicine and Rehabilitation, University of Michigan, Ann Arbor, MI; ${ }^{3}$ De- \\ partment of Veterans Affairs Ann Arbor Healthcare System, Ann Arbor, MI
}

\begin{abstract}
Individuals with the same neurological conditions do not necessarily manifest the same behavioral presentation, which suggests differences in resilience and vulnerability among individuals, a concept known as cognitive reserve. This study sought to explore the relationship among cognitive reserve, executive functioning, and health and safety judgment in a sample of older adult inpatients in an extended medical care unit at a Veterans Health Administration hospital. We hypothesized that cognitive reserve, as determined by an estimate of premorbid intellectual ability, would act as a protective factor against poor judgment in older adults with executive dysfunction. Participants included 200 Veterans who completed a comprehensive neuropsychological assessment, including measures of health and safety judgment, executive functioning, global cognitive functioning, and premorbid intellectual ability. After controlling for global cognitive functioning, executive functioning abilities did not have an effect on judgment abilities among those with high estimated intellectual ability. However, executive functioning had a significant effect on judgment abilities among those with low estimated intellectual ability. Our results suggest that intact executive functioning is critical for making appropriate health and safety decisions for patients with lower measured intellectual abilities and provide further support for the cognitive reserve model. Clinical implications are also discussed.
\end{abstract}

Key words: aging, assessment, cognitive decline, cognitive reserve, executive functioning, health, intellectual ability, judgment, neuropsychology, treatment planning.

\section{INTRODUCTION}

Census data indicate that more than 40 million people aged $65 \mathrm{yr}$ and older were residing in the United States in 2010, representing 13 percent of the total population. This number is predicted to reach more than 72 million by 2030, which will represent about 19 percent of the population [1]. With this dramatic increase in older adults, we can also expect a rise in rates of age-related cognitive impairment, including dementia. Research conducted by the Alzheimer disease (AD) international organization, Alzheimer's Association, predicts that there will be 5.1 million individuals with dementia in North America alone by the year 2020, representing a 49 percent increase in dementia from 2001

\footnotetext{
Abbreviations: $\mathrm{AD}=$ Alzheimer disease; $\mathrm{ADL}=$ activity of daily living; $\mathrm{EF}$ = executive functioning; IADLs = instrumental activities of daily living; ILS = Independent Living Scales; ILS: H\&S = Independent Living Scales: Health and Safety subtest; IQ = intelligence quotient; MMSE = Mini-Mental State Examination; PPVT-IV = Peabody Picture Vocabulary Test, Fourth Edition; RDS = Reliable Digit Span; SD = standard deviation; TMT-B = Trail-Making Test, Part B; VHA = Veterans Health Administration; WAIS-IV DS = Wechsler Adult Intelligence Scale-Fourth Edition Digit Span subtest.

*Address all correspondence to Kristin H. Hinrichs, PhD; SSM-Select Rehabilitation Hospital, 12380 DePaul Dr, Bridgeton, MO 63044; 314-447-9705.

Email: Kristin.h.hinrichs@gmail.com

http://dx.doi.org/10.1682/JRRD.2015.04.0073
} 
to 2020. This rate is predicted to rise to 9.2 million individuals by the year 2040 [2].

A growing body of research suggests that premorbid individual characteristics may be used to identify people at a high risk for developing cognitive impairment [3-5]. Specifically, the theory of cognitive reserve hypothesizes that characteristics such as one's level of education, occupational status, and general intellect are associated with more efficient, resilient neural networks that can serve as protection against the cognitive effects of brain disease or injury. Given that cognitive decline is increasingly prevalent with advancing age, older adults present a particularly appropriate sample in which to study the possibly protective effect of cognitive reserve [6].

Individuals with the same brain pathology or structural damage do not necessarily manifest the same behavioral presentation, which suggests differences in resilience and vulnerability among individuals [4-5,7-8]. This pattern has been observed across a wide range of brain pathologies, including moderate to severe traumatic brain injury [9], cerebrovascular disease [10], hepatitis C [11], and AD [12]. Overall, a strong body of research has found support that intellectual ability, education, and occupational attainment are associated with cognitive reserve [7,11-17]. Though a number of studies have aided in our conceptualization of cognitive reserve over the last decade, the neurocognitive processes involved in maintaining one's functional ability after brain insult or disease is not completely known. Further research on cognitive reserve could be particularly important for the aging population in terms of predicting daily functioning, general safety, and quality of life in the context of conditions that are known or suspected to contribute to cognitive decline (e.g., chronic illnesses, brain injury, neurodegenerative diseases).

One important cognitive function that sometimes declines with advancing age is executive functioning (EF) [18]. EF is characterized as the ability to perform complex, goal-directed, and self-serving tasks and is implicated in our ability to manage daily care demands, such as meal preparation and maintaining a clean home [19-23]. Deficits in EF can affect one's ability to make both simple and complex health and safety decisions and may therefore interfere with both basic activities of daily living (ADLs) and instrumental activities of daily living (IADLs) [24-25]. In older adults, poor EF is related to poorer performance on measures of health and safety judgment [19]. A patient's responses on measures of judgment (i.e., his or her ability to answer a series of health and safety questions such as "What should you do if your house caught on fire?”) can provide invaluable information regarding his or her ability to think through complex tasks, formulate a plan, and carry that plan out. A number of studies have provided similar support for the association between EF and ADLs/IADLs in the general, community-dwelling older adult population [26]; in people with mild dementia [27]; and in people with chronic cardiovascular disease [28]. However, the potential effect of cognitive reserve on the relationship between EF and judgment has not yet been well characterized.

Our study sought to explore the relationship among cognitive reserve, EF, and health and safety judgment among a sample of older adult inpatients of an extended medical care unit at a Veterans Health Administration (VHA) hospital. We hypothesized that cognitive reserve, as measured by performance on a test used to estimate premorbid intelligence, would act as a protective factor against poor judgment in older adults with executive dysfunction. These results will provide better clinical insights for treatment providers in terms of discharge planning for older adult patients.

\section{METHODS}

\section{Participants}

Two hundred inpatients at a Midwestern VHA medical center extended care clinic were included in this study. The extended care clinic provides inpatient rehabilitative therapies to Veterans with a variety of illnesses and disabilities. Participants were primarily male (96\%) and Caucasian (84.5\%), with a mean age of $67.11( \pm 9.5)$ yr and with a mean education of $12.51( \pm 2.6)$ yr. Each patient was administered a brief neuropsychological evaluation as part of routine care to inform treatment and discharge planning. Patients were included in our analyses if they demonstrated that they were able to adequately perceive both visual and auditory stimuli during an initial interview and informal sensory assessment. In the event that deficits were detected, large-sized stimuli (for visual deficits) and a voice amplifier device (for hearing deficits) were used. If the participant was unable to adequately perceive stimuli with these aids, the data were excluded. 


\section{Measures}

Judgment of health and safety behaviors was measured using the Independent Living Scales (ILS): Health and Safety subtest (ILS: H\&S) [29]. ILS: H\&S consists of 20 items that ask individuals how they would respond to various real-life situations, such as recognizing potential health hazards in the home and community environments, with each response eliciting a score from 0 to 2 . Higher scores are indicative of verbally expressed better judgment in the context of health and safety. The ILS: H\&S has been shown to have good test-retest reliability (0.88), good interrater reliability (0.96), good content validity, and high concurrent validity with the ADL domain, a self-report measure of daily living skills [29]. Further, the ILS has also been shown to be a better predictor of legal determinations of competency than the Trail-Making Test and Mini-Mental State Examination (MMSE) in terms of hit rate and predictive value [30]. The ILS was evaluated, along with 30 other measures, in a 2005 review of performance-based measures of functional living skills [31]. The ILS was identified as having good psychometric support and was recommended for assessment of nondisabled older adults, psychiatric patients, and elderly patients with dementia.

In this study, EF was measured using the TrailMaking Test, Part B (TMT-B) [32]. This is a timed test that requires visual scanning, sequencing, and mental setshifting. Scores were calculated using the total time to complete the task with faster times (i.e., lower scores) indicative of better EF. Scores on TMT-B have been found to have moderate correlations with other wellestablished measures of EF, including the Wisconsin Card Sorting Test (0.31) and Category Test (0.38) [33]. The TMT-B was discontinued for performances lasting more than $300 \mathrm{~s}$; performances ranged from 35 to $300 \mathrm{~s}$ in our study. A study by Bell-McGinty et al. found that commonly used neuropsychological tests of EF, including TMT-B and the Wisconsin Card Sorting Test, were useful in predicting functional status for older individuals. Specifically, TMT-B performance was found to be a significant predictor of overall functional status, as measured by the ILS full scale score [19]. (For a comprehensive review of the Trail Making Test, see Strauss et al. [34].)

Premorbid intelligence quotient (IQ) was estimated using the Peabody Picture Vocabulary Test, Fourth Edition (PPVT-IV) [35]. The PPVT-IV is a receptive vocabulary test in which participants match pictures to vocabulary words. Overall performance on the PPVT-IV is represented by a standard score (i.e., mean $=100$, standard deviation $[\mathrm{SD}]=15$ ), with higher scores indicating higher estimated intelligence. Standard scores on the PPVT-IV have been shown to have moderate to high correlations with full scale IQ scores $(r=0.40)$ and verbal IQ scores $(r=0.46)$ derived from the Wechsler Adult Intelligence Scale-Third Edition [36]. The PPVT-IV and its earlier forms have been used to estimate intellectual ability in a number of similar studies [37-38]. As previously mentioned, the estimate of general intelligence is considered a proxy for cognitive reserve in this study.

Global cognitive functioning was measured using the MMSE [39]. The MMSE is a commonly used brief screening tool for cognitive impairment in the domains of orientation, attention, memory, language, and visuospatial abilities. Previous research has demonstrated that scores on the MMSE are related to general cognitive ability even after controlling for education [40]. (For a complete review of the MMSE, see Lezak [22].) Scores range from 0 to 30, and higher scores represent better cognitive functioning.

Task engagement was also measured using Reliable Digit Span (RDS) [41], a measure of performance validity derived from the Wechsler Adult Intelligence ScaleFourth Edition Digit Span subtest (WAIS-IV DS) [42]. RDS was originally developed by Greiffenstein et al. [43] and has been shown to be a useful validity marker across a number of studies [22,41,44]. A cut-off score of less than 7 was used. This score was chosen based on the findings of Axelrod et al., who found that this cut-off resulted in a sensitivity rate of 50.0 percent and specificity rate of 82.8 percent for failed effort based on the use of the Recognition Memory Test and Test of Memory Malingering as criterion measures in a population of probable malingerers [45]. RDS was coded as a dichotomous variable: $0=$ poor task engagement and $1=$ adequate task engagement.

\section{Procedure}

The MMSE, WAIS-IV DS, PPVT-IV, ILS: H\&S, and TMT-B measures were administered, in that order, as part of a larger neuropsychological battery upon admission to the extended care unit to assess emotional and cognitive status and to inform treatment and discharge planning. The battery, which included additional tests that were not used in the present study, was typically administered over the course of a $1 \mathrm{~h}$ appointment and in the aforementioned 
predetermined order, but on occasion it was administered over multiple appointments or in alternative sequence because of patient fatigue or other extenuating care circumstances. Measures were administered and scored by research assistants trained and supervised by two of the authors (N.G. and L.A.B.).

\section{Analysis}

Data analyses were completed using the statistical package SPSS, version 21 (IBM Corporation; Armonk, New York). Cases with data missing on one or more measures were excluded from some of our analyses. Variables were found to be normally distributed; therefore, parametric tests were utilized.

\section{RESULTS}

\section{Preliminary Analyses}

Descriptive statistics are presented in Table 1. Briefly, the mean ILS: H\&S (the outcome variable) score was 31.95. Analyses revealed that the mean premorbid estimated IQ was in the average range (mean $=97.77$; SD = 12.07). Regarding current global cognitive functioning, 94.3 percent of the sample scored within the normal range

Table 1.

Descriptive statistics of participants $(N=200)$.

\begin{tabular}{lc}
\hline \multicolumn{1}{c}{ Variable } & Mean \pm SD or \% \\
\hline Sex & 96 \\
Male & 4 \\
Female & \\
Race & 84.5 \\
White & 11.0 \\
African American & 4.5 \\
Other & $67.11 \pm 9.5$ \\
Age (yr) & $12.51 \pm 2.6$ \\
Education $(\mathrm{yr})$ & $97.49 \pm 11.96$ \\
PPVT-IV & $31.95 \pm 6.04$ \\
ILS: H\&S & $\dagger$ \\
TMT-B $(s)$ & $220.34 \pm 91.68$ \\
MMSE $^{\dagger}$ & $25.72 \pm 4.02$ \\
RDS $<7, n=29^{*}$ & 14.5
\end{tabular}

*Standard score.

${ }^{\dagger}$ Raw score.

ILS: H\&S = Independent Living Scales: Health and Safety subtest; MMSE = Mini-Mental State Examination; PPVT-IV = Peabody Picture Vocabulary Test, Fourth Edition; RDS = Reliable Digit Span; SD = standard deviation; TMT-B = Trail-Making Test, Part B.
(MMSE > 22). Notably, performance on reliable digits indicated that a majority of the sample (85.5\%) demonstrated adequate performance validity during testing. The average completion time of TMT-B was approximately $220 \mathrm{~s}$, which falls roughly in the borderline-impaired range for an adult of the mean age and education level of this sample (scores ranged from 35-300 s).

\section{Determining Covariates}

Multiple regression analyses were used to determine whether age, global cognitive function, and task engagement affected performance on ILS: H\&S, representing significant covariates (Table 2). Analyses revealed that higher levels of global cognitive function predicted better judgment of health and safety behaviors. Specifically, each +1 SD in MMSE corresponded to a 1.75 point $(S D=0.29)$ increase in scores on the ILS: H\&S. Notably, neither age nor task engagement predicted performance on the measure of judgment. Thus, only MMSE score was used as a covariate in the following models.

\section{Main Effects of Premorbid Intellect and Executive Function on Judgment}

Next, we predicted ILS: H\&S scores using IQ and EF as independent variables, while controlling for MMSE (Table 3). The overall model was significant and accounted for approximately 19 percent of the variance in ILS: H\&S scores. In examining individual predictors, analyses revealed better EF was related to better judgment of health and safety behaviors. Specifically, we found that a -1 SD in time to complete TMT-B (92 s) corresponded with better judgment as indicated by a $+0.25 \mathrm{SD}$ in scores on the ILS: H\&S (representing an improvement in overall score of approximately 1.5 points). Similarly, we found

Table 2.

Summary of multiple regression analysis for covariates predicting Independent Living Scales: Health and Safety subtest $(n=137)$.

\begin{tabular}{lc}
\hline \multicolumn{1}{c}{ Variable } & \multicolumn{1}{c}{$\boldsymbol{\beta}$} \\
\hline Age & -0.15 \\
MMSE & $0.29^{*}$ \\
Reliable Digits Cutoff & 0.04 \\
$R$ & $0.14^{\dagger}$ \\
$F$ & $7.10^{*}$ \\
${ }^{*} p<0.01$. & \\
${ }^{\dagger} p<0.05$. & \\
MMSE = Mini-Mental State Examination. \\
\hline \hline
\end{tabular}


Table 3.

Predicting judgment of health and safety behaviors using executive functioning, premorbid intelligence quotient, and current mental status ( $n=$ 127).

\begin{tabular}{|c|c|c|c|c|c|}
\hline Outcome/Predictor & $\boldsymbol{\beta}$ & $t$ & $p$-Value & $F$ & $R^{2}$ \\
\hline Determining Covariates & & & $<0.001$ & 6.50 & 0.13 \\
\hline Age & -0.14 & -1.65 & 0.10 & & \\
\hline MMSE & 0.29 & 3.25 & $<0.01$ & & \\
\hline RDS & $0.65^{*}$ & 0.44 & 0.66 & & \\
\hline Intercept & $24.05^{*}$ & 3.75 & $<0.001$ & & \\
\hline Main Effects & & & $<0.001$ & 9.36 & 0.19 \\
\hline MMSE & 0.09 & 0.93 & 0.35 & & \\
\hline PPVT-IV & 0.19 & 2.10 & 0.04 & & \\
\hline TMT-B & -0.25 & -2.47 & 0.02 & & \\
\hline Intercept & $21.11^{*}$ & 3.11 & $<0.01$ & & \\
\hline Interactive Effects & & & $<0.001$ & 8.31 & 0.21 \\
\hline MMSE & 0.05 & 0.45 & 0.66 & & \\
\hline PPVT-IV & -0.21 & -0.98 & 0.33 & & \\
\hline TMT-B & -1.69 & -2.43 & 0.02 & & \\
\hline PPVT-IV × TMT-B & 1.32 & 2.10 & 0.04 & & \\
\hline Intercept & $44.14^{*}$ & 3.67 & $<0.001$ & & \\
\hline
\end{tabular}

*Unstandardized beta.

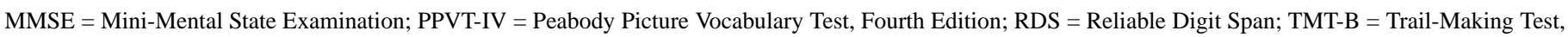
Part B.

that estimated premorbid intelligence was associated with greater health and safety judgment. That is, a +1 SD on the PPVT-IV (an increase of 11.96 estimated IQ points) corresponded to a +0.19 SD (1.15 points) in total score on the ILS: H\&S. Notably, MMSE was no longer a significant predictor of ILS once the effects of EF and premorbid IQ were accounted for.

\section{Interaction Effects}

To examine how cognitive reserve might influence the effect of EF on judgment of health and safety behaviors, we added PPVT-IV $\times$ TMT-B to the model as an interaction term (see the Figure). The overall model was significant, as was the interaction term, and accounted for 22 percent of the variance in the outcome variable.

Among individuals with high cognitive reserve (defined as +1 SD; PPVT-IV = 109.45), judgment of health and safety behaviors did not significantly differ between patients with high EF (defined as +1 SD on TMT-B; ILS: $H \& S=32.22$ ) compared to low EF (defined as -1 SD on TMT-B; ILS: H\&S = 31.75; see the Figure). Conversely, among individuals with low cognitive reserve (PPVT-IV = 85.53), there was a significant difference between individuals with high EF (ILS: H\&S = 31.56) and low EF (ILS:
$H \& S=26.70)$. Of note, the difference in ILS: $H \& S$ between these two patient subgroups was 4.86 , which corresponds to a difference of 0.80 SD in ILS: H\&S scores. Judgment of health and safety behaviors only significantly differed between patients with low cognitive reserve, depending on EF performance.

\section{DISCUSSION}

After controlling for global cognitive functioning, our results revealed that people with high estimated IQ performed similarly on a measure of health and safety judgment, regardless of their EF abilities. However, among individuals with low estimated IQ it appears that intact EF is critical in making appropriate health and safety decisions. Specifically, individuals with low estimated premorbid intelligence, in addition to executive dysfunction, had the lowest scores on a measure of health and safety judgment. Our results provide further support for the cognitive reserve model of individual differences in cognitive decline, particularly in terms of preservation of judgment abilities despite poorer performance in EF for individuals with higher premorbid intelligence. 


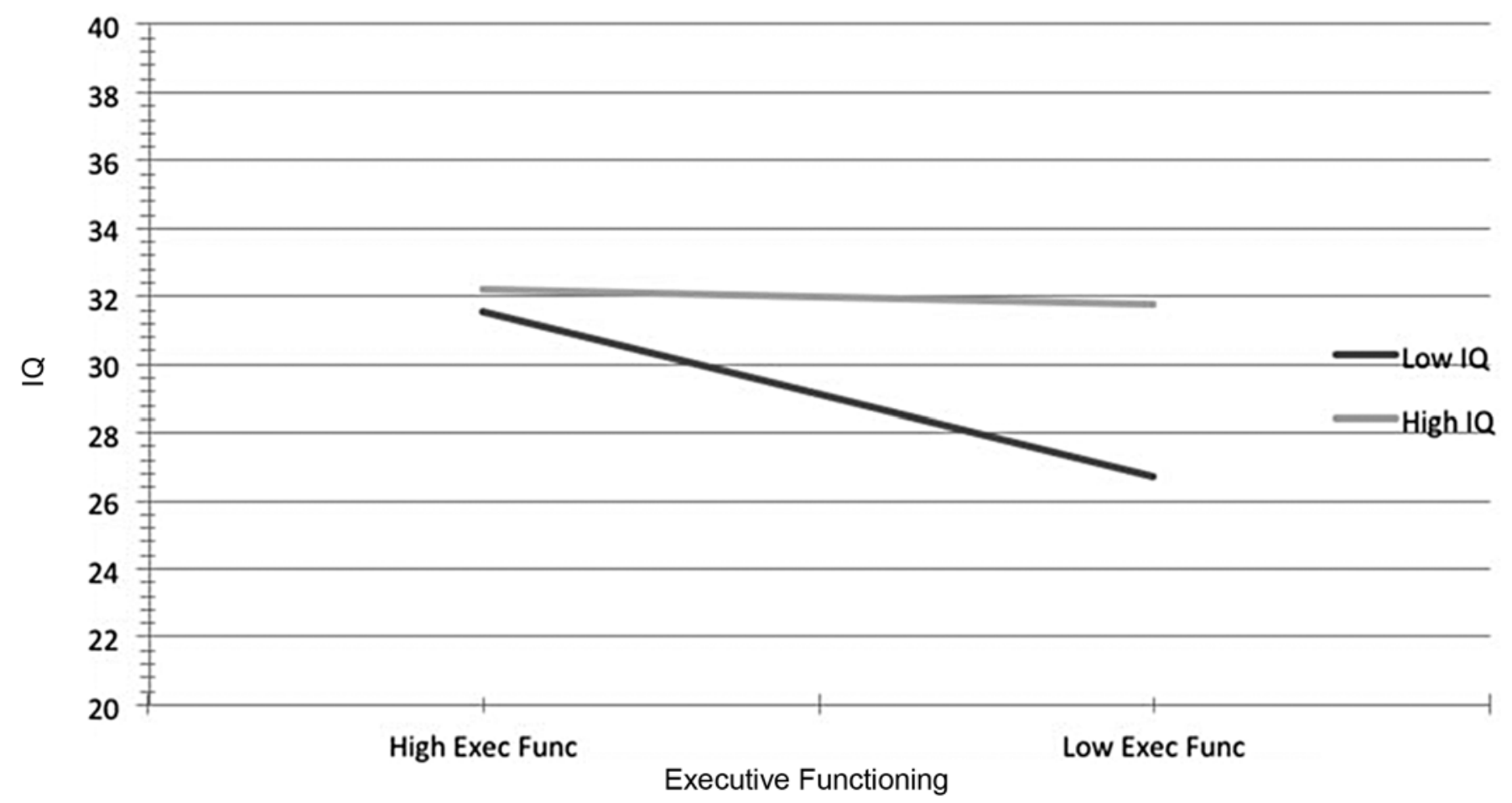

Figure.

Independent Living Scales: Health and Safety subtest scores by executive functioning and intelligence quotient (IQ). Exec Func = executive functioning.

Surprisingly, estimates of global cognitive functioning did not significantly contribute to this relationship, yet screening tools such as the MMSE are used frequently in medical settings to guide treatment planning [46]. Past research has demonstrated that the MMSE has a particularly high false-negative rate for patients with executive dysfunction [47], which may explain its insignificant effect on judgment in the current study. Age did not appear to have a significant effect on judgment. This is consistent with previous findings that suggest that while cognitive abilities such as working memory and EF decline with age, skills required to make social judgments often do not [48]. This is thought to be related to intact brain regions associated with emotion processing (i.e., amygdala) and with emotional decision making (i.e., ventromedial prefrontal area) [48-49].

Our findings have significant implications for health and safety outcomes and treatment planning for individuals who may have compromised EF abilities. As in our sample, many geriatric and chronically ill patients are admitted to extended care facilities where medical professionals must decide the logical next step to insure safety and to decrease the chances of readmission to a medical facility and other negative outcomes. Although the recommended next step can sometimes include skilled nursing facilities, hospice, or placement with a family member, patients often express a desire to continue to reside in their homes and manage their care independently. This conflict places providers managing discharge plans in a delicate situation in which they must attempt to predict a patient's ability to make sound decisions regarding his or her safety, health, and finances. With formal neuropsychological testing, along with research findings such as the ones described in this study, providers may make more informed and appropriate decisions regarding discharge placement. For example, despite executive dysfunction, a patient with high intellectual functioning may maintain his or her judgment skills because of cognitive reserve and perhaps could live independently with additional support from family or home healthcare visits. A patient with low intellectual functioning and therefore less cognitive reserve appears less likely to retain his or her decision-making capacity in the context of executive 
dysfunction, and therefore would likely need additional resources and supervision to ensure safety. Although both patients may perform similarly on an EF measure, such as TMT-B, cognitive reserve may make a significant difference in each of their functional abilities. This observation may be similar to a reported relationship between speed of information processing and a person's education (a proxy for cognitive reserve and related to the effect of white matter changes in the brain); higher levels of white matter abnormalities correspond to slower processing speed in lower-educated individuals, while the relationship is attenuated in those with higher levels of education [50]. In other words, compensatory processes are increased in those with higher cognitive reserve.

\section{CONCLUSIONS}

Whereas identifying older patients with cognitive impairment is important in terms of postdischarge health and safety, identifying those who are cognitively intact is also important in order to preserve functional independence as long as possible. Negative consequences associated with removing independence can include isolation, disruption of social support networks, and depression [51]. The results of this study can provide aid in identifying both types of patients: those who need a significant intervention in their living arrangements and those who can successfully maintain independence without compromising their health and safety.

We acknowledge that our findings cannot be generalized to all individuals; however, these findings add to our understanding of how some older chronically ill patients are able to retain their independence and decisionmaking capabilities better than others. Additionally, EF and judgment of health and safety are just two of the many factors that contribute to one's safety and independence. Future studies will be imperative to further understand the process of maintaining function in older adults and to help improve the well-being and quality of life for this population.

The findings of our study also serve to improve the understanding of cognitive reserve and aging. We have learned, through a large body of research on cognitive reserve, that quantifiable differences exist that make one more or less likely to display functional impairment in the event of traumatic brain injury, AD, stroke, or any number of other brain pathologies [4]. Future studies will be necessary to replicate and extend the results reported thus far. Through such work, we can improve our models of cognitive reserve and use this knowledge to help improve the daily functioning, and thus the quality of life, for individuals with neurological conditions. Specifically, future studies should focus attention on the cognitive skills retained that may compensate for loss of EF abilities (e.g., fluid reasoning ability, long-term memory). Once these skills are identified, efforts can be made to maintain or improve such cognitive abilities in patients at risk.

We acknowledge that our study design had several limitations. From a measurement perspective, scores on two of our assessment instruments may have been influenced by information processing speed ability (TMT-B and aspects of WAIS-IV DS). Although we controlled for global cognitive functioning (with total MMSE scores), we did not specifically examine the effects of information processing speed. An additional limitation is that our sample characteristics may have an effect on the generalizability of these results. Although our study sample was large and demonstrated estimated intellectual ability consistent with the general population, other features of our sample make it unique. Specifically, participants were patients at a VHA hospital in the Midwest, which serves only those with a history of military service, and were predominantly male (96\%). These patients also have a number of chronic comorbid health conditions, including diabetes (and associated amputations), high blood pressure, cardiovascular disease, and chronic obstructive pulmonary disease. These conditions and the medications used to treat them have been linked to cognitive impairment [52-55]. Future research may include sex, specific medical conditions, and medication effects as potential confounding factors that may affect generalizability to community-dwelling and other older populations. Although we did not attempt to address the role of psychiatric diagnoses in the present study, such illnesses may have additional influence on performance of a judgment task. Although these limitations may make our findings unique, they are likely very generalizable to other VHA facilities and inpatient extended care clinics. Our sample was medically and psychiatrically complex with a variety of chronic and acute conditions. As such, our findings may be helpful in treatment and discharge planning for a large number of individuals with similarly complex conditions for whom planning tends to be exceptionally difficult. 


\section{ACKNOWLEDGMENTS}

\section{Author Contributions:}

Study concept and design: K. H. Hinrichs, A. Hayek, N. Gabel. Acquisition of data: K. H. Hinrichs, A. Hayek.

Analysis and interpretation of data: D. Kalmbach.

Drafting of manuscript: K. H. Hinrichs, A. Hayek, D. Kalmbach,

N. Gabel.

Critical revision of manuscript for important intellectual content:

N. Gabel, L. A. Bieliauskas.

Statistical analysis: D. Kalmbach.

Study supervision: N. Gabel, L. A. Bieliauskas.

Financial Disclosures: The authors have declared that no competing interests exist.

Funding/Support: This material was unfunded at the time of manuscript preparation.

Additional Contributions: Since the completion of this study, Drs. Hinrichs and Kalmbach have obtained PhDs and Mr. Hayek has obtained a BS. Dr. Hinrichs is now with SSM-Select Rehabilitation Hospital in Bridgeton, Missouri, and Mr. Hayek is now with Michigan State School of Medicine in East Lansing, Michigan.

Institutional Review: The parent study was approved by the institutional review board at the VA Ann Arbor Healthcare System. The plan for this research project was reviewed by the institutional review board and no additional subject consent was required.

Participant Follow-Up: Because this was a retrospective study, the participants will not be informed of the results of this study.

\section{REFERENCES}

1. Administration on Aging. Aging statistics [Internet]. Washington (DC): Administration for Community Living, U.S. Department of Health and Human Services [updated 2016 May 24; cited 2015 Mar 31]. Available from: http://www.aoa.acl.gov/Aging Statistics/index.aspx

2. Ferri CP, Prince M, Brayne C, Brodaty H, Fratiglioni L, Ganguli M, Hall K, Hasegawa K, Hendrie H, Huang Y, Jorm A, Mathers C, Menezes PR, Rimmer E, Scazufca M; Alzheimer's Disease International. Global prevalence of dementia: A Delphi consensus study. Lancet. 2005; 366(9503):2112-17. [PMID:16360788] http://dx.doi.org/10.1016/S0140-6736(05)67889-0

3. Barnett JH, Salmond CH, Jones PB, Sahakian BJ. Cognitive reserve in neuropsychiatry. Psychol Med. 2006;36(8): 1053-64. [PMID:16854246] http://dx.doi.org/10.1017/S0033291706007501

4. Richards M, Deary IJ. A life course approach to cognitive reserve: A model for cognitive aging and development? Ann Neurol. 2005;58(4):617-22. [PMID:16178025] http://dx.doi.org/10.1002/ana.20637

5. Tucker AM, Stern Y. Cognitive reserve in aging. Curr Alzheimer Res. 2011;8(4):354-60. [PMID:21222591] http://dx.doi.org/10.2174/156720511795745320
6. Park HL, O'Connell JE, Thomson RG. A systematic review of cognitive decline in the general elderly population. Int $\mathrm{J}$ Geriatr Psychiatry. 2003;18(12):1121-34. [PMID:14677145] http://dx.doi.org/10.1002/gps.1023

7. Mortimer JA, Snowdon DA, Markesbery WR. Head circumference, education and risk of dementia: Findings from the Nun Study. J Clin Exp Neuropsychol. 2003;25(5):671-79. [PMID:12815504] http://dx.doi.org/10.1076/jcen.25.5.671.14584

8. Valenzuela MJ, Sachdev P. Brain reserve and dementia: A systematic review. Psychol Med. 2006;36(4):441-54. [PMID:16207391] http://dx.doi.org/10.1017/S0033291705006264

9. Kesler SR, Adams HF, Blasey CM, Bigler ED. Premorbid intellectual functioning, education, and brain size in traumatic brain injury: An investigation of the cognitive reserve hypothesis. Appl Neuropsychol. 2003;10(3):153-62. [PMID:12890641]

10. Murray AD, Staff RT, McNeil CJ, Salarirad S, Ahearn TS, Mustafa N, Whalley LJ. The balance between cognitive reserve and brain imaging biomarkers of cerebrovascular and Alzheimer's diseases. Brain. 2011;134(12):3687-96. [PMID:22102649] http://dx.doi.org/10.1093/brain/awr259

11. Bieliauskas LA, Back-Madruga C, Lindsay KL, Snow KK, Kronfol Z, Lok AS, Padmanabhan L, Fontana RJ. Clinical relevance of cognitive scores in hepatitis $C$ patients with advanced fibrosis. J Clin Exp Neuropsychol. 2006;28(8): 1346-61. [PMID:17050262] http://dx.doi.org/10.1080/13803390500473720

12. Stern Y, Gurland B, Tatemichi TK, Tang MX, Wilder D, Mayeux R. Influence of education and occupation on the incidence of Alzheimer's disease. JAMA. 1994;271(13): 1004-10. [PMID:8139057] http://dx.doi.org/10.1001/jama.1994.03510370056032

13. Albert MS, Jones K, Savage CR, Berkman L, Seeman T, Blazer D, Rowe JW. Predictors of cognitive change in older persons: MacArthur studies of successful aging. Psychol Aging. 1995;10(4):578-89. [PMID:8749585] http://dx.doi.org/10.1037/0882-7974.10.4.578

14. Alexander GE, Furey ML, Grady CL, Pietrini P, Brady DR, Mentis MJ, Schapiro MB. Association of premorbid intellectual function with cerebral metabolism in Alzheimer's disease: Implications for the cognitive reserve hypothesis. Am J Psychiatry. 1997;154(2):165-72. [PMID:9016263] http://dx.doi.org/10.1176/ajp.154.2.165

15. Katzman R. Education and the prevalence of dementia and Alzheimer's disease. Neurology. 1993;43(1 Part 1):13-20. [PMID:8423876] http://dx.doi.org/10.1212/WNL.43.1 Part 1.13

16. Satz P, Morgenstern H, Miller EN, Selnes OA, McArthur JC, Cohen BA, Wesch J, Becker JT, Jacobson L, D’Elia LF, van Gorp W, Visscher B. Low education as a possible risk factor for cognitive abnormalities in HIV-1: Findings from 
the multicenter AIDS Cohort Study (MACS). J Acquir Immune Defic Syndr. 1993;6(5):503-11. [PMID:8483113]

17. Meng X, D’Arcy C. Education and dementia in the context of the cognitive reserve hypothesis: A systematic review with meta-analyses and qualitative analyses. PLoS ONE. 2012;7(6):e38268. [PMID:22675535]

http://dx.doi.org/10.1371/journal.pone.0038268

18. Fisk JE, Sharp CA. Age-related impairment in executive functioning: Updating, inhibition, shifting, and access. J Clin Exp Neuropsychol. 2004;26(7):874-90. [PMID:15742539] http://dx.doi.org/10.1080/13803390490510680

19. Bell-McGinty S, Podell K, Franzen M, Baird AD, Williams MJ. Standard measures of executive function in predicting instrumental activities of daily living in older adults. Int J Geriatr Psychiatry. 2002;17(9):828-34. [PMID:12221656] http://dx.doi.org/10.1002/gps.646

20. Royall DR, Mulroy AR, Chiodo LK, Polk MJ. Clock drawing is sensitive to executive control: A comparison of six methods. J Gerontol B Psychol Sci Soc Sci. 1999;54B(5): P328-33. [PMID:10542825]

http://dx.doi.org/10.1093/geronb/54B.5.P328

21. Malloy PF, Richardson ED. The frontal lobes and contentspecific delusions. J Neuropsychiatry Clin Neurosci. 1994; 6(4):455-66. [PMID:7841816] http://dx.doi.org/10.1176/jnp.6.4.455

22. Lezak MD. Neuropsychological assessment. 4th ed. New York (NY): Oxford University Press; 2004.

23. Brennan M, Welsh MC, Fisher CB. Aging and executive function skills: An examination of a community-dwelling older adult population. Percept Mot Skills. 1997;84(3c): 1187-97. [PMID:9229435] http://dx.doi.org/10.2466/pms.1997.84.3c.1187

24. Burgess PW, Alderman N, Evans J, Emslie H, Wilson BA. The ecological validity of tests of executive function. J Int Neuropsychol Soc. 1998;4(6):547-58. [PMID:10050359] http://dx.doi.org/10.1017/S1355617798466037

25. Grigsby J, Kaye K, Baxter J, Shetterly SM, Hamman RF. Executive cognitive abilities and functional status among community-dwelling older persons in the San Luis Valley Health and Aging Study. J Am Geriatr Soc. 1998;46(5): 590-96. [PMID:9588372] http://dx.doi.org/10.1111/j.1532-5415.1998.tb01075.x

26. Johnson JK, Lui L-Y, Yaffe K. Executive function, more than global cognition, predicts functional decline and mortality in elderly women. J Gerontol A Biol Sci Med Sci. 2007;62(10):1134-41. [PMID:17921427]

http://dx.doi.org/10.1093/gerona/62.10.1134

27. Razani J, Casas R, Wong JT, Lu P, Alessi C, Josephson K. Relationship between executive functioning and activities of daily living in patients with relatively mild dementia. Appl Neuropsychol. 2007;14(3):208-14. [PMID:17848131] http://dx.doi.org/10.1080/09084280701509125
28. Jefferson AL, Paul RH, Ozonoff A, Cohen RA. Evaluating elements of executive functioning as predictors of instrumental activities of daily living (IADLs). Arch Clin Neuropsychol. 2006;21(4):311-20. [PMID:16814980]

http://dx.doi.org/10.1016/j.acn.2006.03.007

29. Loeb PA. Independent Living Scales (ILS) manual. San Antonio (TX): Psychological Corporation; 1996. 112 p.

30. Quickel EJ, Demakis GJ. The Independent Living Scales in civil competency evaluations: Initial findings and prediction of competency adjudication. Law Hum Behav. 2013; 37(3):155-62. [PMID:22906190] http://dx.doi.org/10.1037/lhb0000009

31. Moore DJ, Palmer BW, Patterson TL, Jeste DV. A review of performance-based measures of functional living skills. J Psychiatr Res. 2007;41(1-2):97-118. [PMID:16360706] http://dx.doi.org/10.1016/j.jpsychires.2005.10.008

32. Reitan RM, Wolfson D. The Halstead-Reitan neuropsychological test battery: Theory and clinical interpretation. Tucson (AZ): Neuropsychology Press; 1985.

33. O’donnell JP, Macgregor LA, Dabrowski JJ, Oestreicher JM, Romero JJ. Construct validity of neuropsychological tests of conceptual and attentional abilities. J Clin Psychol. 1994;50(4):596-600. [PMID:7983209]

http://dx.doi.org/10.1002/1097-4679(199407)50:4<596::AIDJCLP2270500416>3.0.CO;2-S

34. Strauss E, Sherman EM, Spreen O. A compendium of neuropsychological tests: Administration, norms, and commentary. 3rd ed. New York (NY): Oxford University Press; 2007.

35. Dunn L, Dunn D. Peabody Picture Vocabulary Test, 4th edition (PPVT-4). Minneapolis (MN): Pearson Assessments; 2006.

36. Bell NL, Lassiter KS, Matthews TD, Hutchinson MB. Comparison of the Peabody Picture Vocabulary TestThird Edition and Wechsler Adult Intelligence ScaleThird Edition with university students. J Clin Psychol. 2001;57(3):417-22. [PMID:11241372]

http://dx.doi.org/10.1002/jclp.1024

37. Siedlecki KL, Stern Y, Reuben A, Sacco RL, Elkind MS, Wright CB. Construct validity of cognitive reserve in a multiethnic cohort: The Northern Manhattan Study. J Int Neuropsychol Soc. 2009;15(4):558-69. [PMID:19573274] http://dx.doi.org/10.1017/S1355617709090857

38. Snitz BE, Bieliauskas LA, Crossland AR, Basso MR, Roper B. PPVT-R as an estimate of premorbid intelligence in older adults. Clin Neuropsychol. 2000;14(2):181-86. [PMID:10916192]

http://dx.doi.org/10.1076/1385-4046(200005)14:2;1-Z;FT181

39. Folstein MF, Folstein SE, McHugh PR. "Mini-mental state.” A practical method for grading the cognitive state of patients for the clinician. J Psychiatr Res. 1975;12(3):189-98.

[PMID:1202204] http://dx.doi.org/10.1016/0022-3956(75)90026-6 
40. Bieliauskas LA, Depp C, Kauszler ML, Steinberg BA, Lacy M. IQ and scores on the Mini-Mental State Examination (MMSE). Neuropsychol Dev Cogn B Aging Neuropsychol Cogn. 2000;7(4):227-29. http://dx.doi.org/10.1076/anec.7.4.227.799

41. Greiffenstein MF, Gola T, Baker WJ. MMPI-2 validity scales versus domain specific measures in detection of factitious traumatic brain injury. Clin Neuropsychol. 1995;9(3):230-40. http://dx.doi.org/10.1080/13854049508400485

42. Wechsler D. Wechsler Adult Intelligence Scale-Fourth Edition (WAIS-IV). San Antonio (TX): NCS Pearson; 2008.

43. Greiffenstein MF, Baker WJ, Gola T. Validation of malingered amnesia measures with a large clinical sample. Psychol Assess. 1994;6(3):218-24.

http://dx.doi.org/10.1037/1040-3590.6.3.218

44. Meyers JE, Volbrecht M. Validation of reliable digits for detection of malingering. Assessment. 1998;5(3):303-07. [PMID:9786719]

http://dx.doi.org/10.1177/107319119800500309

45. Axelrod BN, Fichtenberg NL, Millis SR, Wertheimer JC. Detecting incomplete effort with Digit Span from the Wechsler Adult Intelligence Scale-Third Edition. Clin Neuropsychol. 2006;20(3):513-23. [PMID:16895862] http://dx.doi.org/10.1080/13854040590967117

46. Brown T, Joliffe L, Fielding L. Is the Mini Mental Status Examination (MMSE) associated with inpatients' functional performance? Phys Occup Ther Geriatr. 2014;32(3): 228-40. http://dx.doi.org/10.3109/02703181.2014.931504

47. Roper BL, Bieliauskas LA, Peterson MR. Validity of the Mini-Mental State Examination and the neurobehavioral cognitive status examination in cognitive screening. Cogn Behav Neurol. 1996;9(1):54-57.

48. MacPherson SE, Phillips LH, Della Sala S. Age, executive function, and social decision making: A dorsolateral prefrontal theory of cognitive aging. Psychol Aging. 2002; 17(4):598-609. [PMID:12507357] http://dx.doi.org/10.1037/0882-7974.17.4.598

49. Charles ST, Mather M, Carstensen LL. Aging and emotional memory: The forgettable nature of negative images for older adults. J Exp Psychol Gen. 2003;132(2):310-24. [PMID:12825643]

50. Nebes RD, Meltzer CC, Whyte EM, Scanlon JM, Halligan EM, Saxton JA, Houck PR, Boada FE, Dekosky ST. The relation of white matter hyperintensities to cognitive performance in the normal old: Education matters. Neuropsychol Dev Cogn B Aging Neuropsychol Cogn. 2006;13(3-4):326-40.

[PMID:16887777]

http://dx.doi.org/10.1080/138255890969294

51. Gabriel Z, Bowling A. Quality of life from the perspectives of older people. Ageing Soc. 2004;24(05):675-91. http://dx.doi.org/10.1017/S0144686X03001582

52. Breteler MM, Claus JJ, Grobbee DE, Hofman A. Cardiovascular disease and distribution of cognitive function in elderly people: The Rotterdam Study. BMJ. 1994; 308(6944):1604-08. [PMID:8025427]

http://dx.doi.org/10.1136/bmj.308.6944.1604

53. Incalzi RA, Gemma A, Marra C, Muzzolon R, Capparella O, Carbonin P. Chronic obstructive pulmonary disease. An original model of cognitive decline. Am Rev Respir Dis. 1993;148(2):418-24. [PMID:8342906] http://dx.doi.org/10.1164/ajrccm/148.2.418

54. Tzourio C, Dufouil C, Ducimetière P, Alpérovitch A. Cognitive decline in individuals with high blood pressure: A longitudinal study in the elderly. EVA Study Group. Epidemiology of Vascular Aging. Neurology. 1999;53(9):1948-52.

[PMID:10599763]

http://dx.doi.org/10.1212/WNL.53.9.1948

55. Stewart R, Liolitsa D. Type 2 diabetes mellitus, cognitive impairment and dementia. Diabet Med. 1999;16(2):93-112. [PMID:10229302] http://dx.doi.org/10.1046/j.1464-5491.1999.00027.x

Submitted for publication April 30, 2015. Accepted in revised form August 31, 2015.

This article and any supplementary material should be cited as follows:

Hinrichs KH, Hayek A, Kalmbach D, Gabel N, Bieliauskas LA. Cognitive reserve and executive function: Effect on judgment of health and safety. J Rehabil Res Dev. 2016;53(6):863-72.

http://dx.doi.org/10.1682/JRRD.2015.04.0073

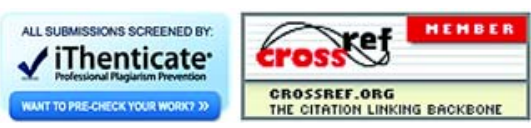

